\title{
The cost of lost productivity due to premature lung cancer-related mortality: results from Spain over a 10-year period
}

\author{
Josep Darbà $^{1 *}$ and Alicia Marsà
}

\begin{abstract}
Background: Cancer mortality is one of the major causes of productivity loss; and within all cancer sites, malignant neoplasms of the lung continue to be the principal cancer-related cause of death in Spain, with a survival rate of only $10.7 \%$. Thus its effects in labour productivity are a major concern and represent a great social impact. The objective of this study was to evaluate the productivity losses that occur as a result of premature deaths due to lung cancer in Spain.

Methods: The human capital approach was used to calculate the costs derived from the premature mortality due to lung cancer, via the extraction of data on mortality, reference salaries and unemployment rates.

Results: Deaths due to lung cancer represented the $28.90 \%$ and the $10.83 \%$ of all cancer-related deaths in 2017 in males and females respectively, with an increasing tendency in this last group. In addition, the YPPLL count increased in the study period among females. Lung cancer was responsible annually for 60,846 YPPLL, and productivity losses summed $€ 13.1$ billion over the 10 year period.
\end{abstract}

Conclusions: The assessment of productivity losses due to lung cancer provides new information that may assist decision makers in the allocation of resources, reducing the burden it supposes in working-age individuals.

Keywords: Lung cancer, Years of potential productive life lost, Productivity costs, Human capital approach

\section{Background}

Lung cancer is the fourth most prevalent cancer among males in Spain, the ninth in women, and the leading cancer-related cause of death in males [1]. Worldwide, tracheal, bronchus and lung cancers were the leading cancer-related cause of death for both males and females in 2013 [2], indeed, in Spain, the 5 year survival rate is only $10.7 \%$ [3].

Lung cancer mortality peaks in individuals aged 75 to 79 years in developed countries as the United Kingdom [4]; however, worldwide, the highest rates are observed in males between 60 and 75 years of age [5]. Altogether, deaths prior 65 years of age have a notorious impact on economic productivity, in which cancer plays a great role [6]. In males, cancers of the trachea, bronchus and lung

\footnotetext{
* Correspondence: darba@ub.edu

${ }^{1}$ Department of Economics, Universitat de Barcelona, Diagonal 696, 08034

Barcelona, Spain

Full list of author information is available at the end of the article
}

together were the leading cause of disability-adjusted life-years (DALYs), which combine health loss with premature mortality, accounting for 34.7 million DALYs in $2013,62 \%$ of those in developing countries and $38 \%$ in developed countries [2].

Estimations of productivity loss provide valuable data for informed resource allocation. Distinct approaches are used to estimate lost productivity. The human capital approach is the majority method, based on the assumption that individuals have a potential productivity to their retirement age that is reduced due to illness or death, leading to losses that can be quantified [7]. Secondarily, the friction cost approach is centred on the losses that take place in the time it takes to replace a worker; this method aims to provide a more realistic calculation, however, it requires the use of a standard measurement of replacement time [8]. Finally, other methods exist focusing on different variables, for instance the willingness to pay approach values immaterial costs as pain and distress [9]. 
Altogether, predictions of cancer mortality-related productivity loss have been projected for various countries $[10,11]$. In Spain, the estimated losses due to cancer temporary disability were $€ 248.6$ million in 2005 [12], added to the $€ 2.5$ billion in losses due to premature mortality estimated in 2009 [13]. The scale of such costs demonstrates the extent of the burden of cancer and the possible economic gains that could be reached by the implementation of informed policies that reduce the incidence of the cancers causing the most expenses.

The present study aimed to evaluate the losses in terms of productivity that occur as a result of premature deaths due to lung cancer in Spain.

\section{Materials and methods}

\section{Study design}

This study was developed based on the human capital approach to calculate the costs derived from premature mortality due to lung cancer, considering the income and contribution to the nation productivity of an individual that are prevented when a premature death occurs. This method was selected taking into account previous studies in the country, and looking to provide a calculation from the worker's perspective.

Mortality data and reference salaries per age group were obtained from the Spanish National Statistics Institute (INE) $[14,15]$. The years of potential productive life lost (YPPLLs) due to premature mortality from lung cancer were estimated by multiplying the number of lung cancer-specific deaths for a given age group by the expected productive years remaining for each group. Retirement age was fixed at 65 years.

To obtain an estimation of costs of premature mortality, age- and sex-specific annual wages from death age to age of retirement were used. YPPLL was corrected per age- and gender-specific unemployment rates [16] and an annual discount rate of $3 \%$ was applied to future income values. A sensitivity analysis was conducted considering two alternative discount rates (0 and 6\%).

\section{Results}

In total, 212,632 people died of lung cancer in Spain between 2008 and 2017, 69,225 during working age. Deaths due to lung cancer represented $28.90 \%$ of all cancer-related deaths in 2017 in males and $10.83 \%$ in females, with an increasing tendency in this last case (Table 1). The year 2008 displayed the highest number of YPPLLs for males, 49,654, while the highest number in females was observed the last year of the study period, 23,035 measured in 2016. Altogether, the average annual YPPLL count was 60,846 .

The year 2017 was considered the reference year in the analysis of the age distribution of YPPLL. Premature mortality in the age period between 50 and 59 years accounted for the highest values of YPPLL (Fig. 1).

The costs of premature mortality were estimated, projecting productivity losses to retirement years and adjusting all calculations per age- and sex-specific annual wages. The analysis provided three estimations, a baseline, and the results of the sensitivity analysis. The accumulated productivity losses from 2008 to 2017 due to lung cancer were $€ 13.1$ billion (Table 2). The sensitivity analysis determined a range between $€ 12.8$ and $€ 13.5$ billion. The amount of losses derived from males was significantly higher than that derived from women, yet in both cases losses showed a decreasing tendency over the study period. The lost productivity measured in males in 2017 was of $€ 899$ million, while in females it was €284 million.

Productivity losses derived from total cancer-related mortality were calculated in order to assess this data in context. Lung cancer accounted for $22.33 \%$ of the losses

Table 1 Indicators of deaths, portion of cancer-related deaths attributable to lung cancer and years of potential productive life lost (YPPLL) due to lung cancer

\begin{tabular}{|c|c|c|c|c|c|c|c|c|c|c|}
\hline Year & 2008 & 2009 & 2010 & 2011 & 2012 & 2013 & 2014 & 2015 & 2016 & 2017 \\
\hline \multicolumn{11}{|c|}{ Number of deaths } \\
\hline males & 17,150 & 17,279 & 17,285 & 17,479 & 17,661 & 17,559 & 17,194 & 17,239 & 17,598 & 17,241 \\
\hline females & 3049 & 3122 & 3447 & 3579 & 3826 & 4105 & 4057 & 4357 & 4557 & 4848 \\
\hline \multicolumn{11}{|c|}{ Deaths at working age } \\
\hline males & 5613 & 5564 & 5520 & 5468 & 5535 & 5252 & 5064 & 5015 & 5004 & 4697 \\
\hline females & 1290 & 1321 & 1495 & 1497 & 1657 & 1736 & 1680 & 1902 & 1918 & 1997 \\
\hline \multicolumn{11}{|c|}{$\%$ of lung cancer related deaths } \\
\hline males & 28.43 & 26.61 & 27.94 & 33.61 & 26.95 & 27.59 & 34.38 & 25.46 & 25.65 & 28.90 \\
\hline females & 7.68 & 8.29 & 8.39 & 10.54 & 9.37 & 9.75 & 10.22 & 9.98 & 10.91 & 10.83 \\
\hline \multicolumn{11}{|l|}{ YPPLL } \\
\hline males & 49,654 & 47,097 & 46,225 & 46,239 & 46,455 & 43,281 & 40,852 & 40,065 & 38,757 & 36,246 \\
\hline females & 15,210 & 15,368 & 16,430 & 16,126 & 17,491 & 17,708 & 16,390 & 18,076 & 17,754 & 23,035 \\
\hline
\end{tabular}




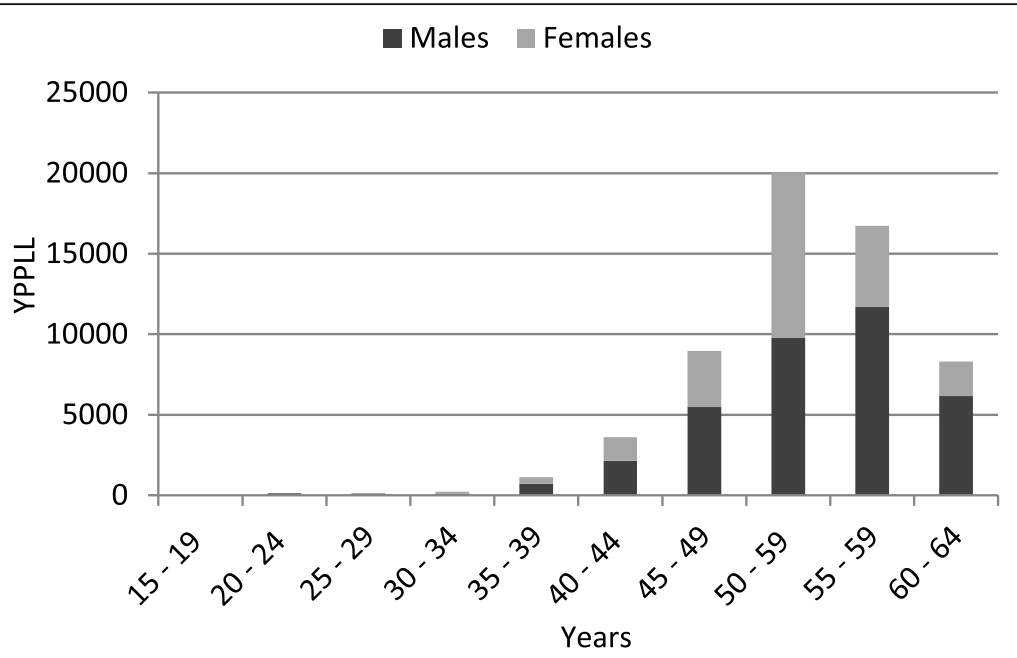

Fig. 1 Years of potential productive life lost (YPPLL) due to premature mortality from lung cancer per age groups in 2017

in 2017, and lost productivity derived from lung cancer peaked the year 2010 when it represented $32.72 \%$ of losses (Fig. 2).

\section{Discussion}

Cancer mortality has been pointed out as one of the major causes of productivity loss [12]. Hence, the increasing interest on measuring and quantifying its economic and social impact.

In general calculations, the productivity loss linked to tumours has been estimated to rise up to hundreds of billions of dollars. The year 2000, the productivity losses associated with cancer only in the United States summed $\$ 116$ billion and were projected to increase to $\$ 148$ billion in 2020 [6]. Conversely, in Australia, estimations lower this sum to around $\$ 4.2$ billion, and 88,000 YPPLLs, presumably an effect of the smaller population [11]. The same study remarked lung cancer as one of the malignancies accounting for the highest portion of costs, in line with former findings in health loss and premature mortality [2]. Lung cancer is, in many countries, the most prevalent cancer type among males, and the principal cancer-related cause of death [17-19]. A study developed in 30 European countries, cancer was appointed responsible for losses of $€ 75$ billion, with lung cancer representing $23 \%$ of total costs [18], while another study centred in the EU measured $€ 126$ billion in losses, with lung cancer representing $15 \%$ of the total [19]. In the present study, losses attributable to lung cancer represented $22.33 \%$ of all cancer-related losses in 2017.

Similarly, a revision of data in Spain linked cancer to $43.5 \%$ of deaths at working age, accounting for 298,753 YPPLL in 2009 and $€ 2.5$ billion in losses [10]. Herein, lung cancer alone represented 36,246 YPPLL for males and 23, 035 for females in 2017; and its costs summed $€ 1.4$ billion that year, $€ 13.1$ billion over a ten year period. The differences observed in the number of YPPLL between males and females, as well as the opposed tendencies are presumably

Table 2 Productivity losses (in millions) of lung cancer (sensitivity models 0\%; 6\%) and percentage of mortality costs of all diseases

\begin{tabular}{|c|c|c|c|c|c|c|}
\hline \multirow[t]{2}{*}{ Year } & \multicolumn{2}{|c|}{ Premature mortality costs (baseline) } & \multicolumn{2}{|c|}{ Premature mortality costs (0\%) } & \multicolumn{2}{|c|}{ Premature mortality costs (6\%) } \\
\hline & Males & Females & Males & Females & Males & Females \\
\hline 2008 & 1245 & 319 & 1278 & 327 & 1214 & 310 \\
\hline 2009 & 1182 & 244 & 1213 & 251 & 1153 & 237 \\
\hline 2010 & 1159 & 228 & 1190 & 234 & 1130 & 222 \\
\hline 2011 & 1140 & 219 & 1170 & 225 & 1112 & 213 \\
\hline 2012 & 1158 & 174 & 1189 & 178 & 1129 & 169 \\
\hline 2013 & 1078 & 170 & 1107 & 174 & 1052 & 164 \\
\hline 2014 & 1019 & 164 & 1045 & 169 & 993 & 161 \\
\hline 2015 & 998 & 225 & 1024 & 231 & 974 & 218 \\
\hline 2016 & 963 & 254 & 988 & 261 & 939 & 247 \\
\hline 2017 & 899 & 284 & 923 & 291 & 877 & 277 \\
\hline Total & 10,841 & 2281 & 11,126 & 2342 & 10,573 & 2218 \\
\hline
\end{tabular}




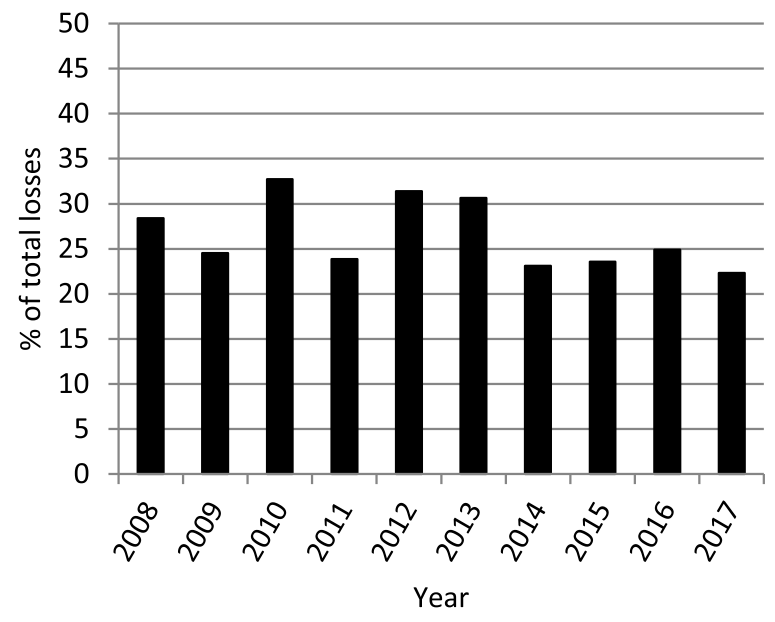

Fig. 2 Portion of total cancer-related losses attributable to lung cancer (2008-2017)

derived from the difference in smoking habits and other trends that promote an increasing incidence among women [20]. However, in the calculation of losses, the significantly different wages for males and females in Spain play an important role and distort any interpretation of mortality trends [16].

Interestingly, $€ 2.1$ billion in productivity losses were estimated for women with breast cancer in Spain in 2014 [21], an elevated figure presumably due to the prevalence of this cancer type in females. It must be considered that the human capital approach allows an estimation of losses that provides a general vision of disease burden, but comparisons among different studies can become a limitation. In addition, it attributes a greater weight to deaths affecting young working males, versus groups with lower employment rates or income, and thus leading to underestimates and overestimates [16]; its use is nonetheless generalised in the recent literature given its efficacy [22].

On the other hand, further considerations including a calculation of DALYs could be of interest to estimate the social impact of lung cancer, since early onsets of the disease may lead primarily to an incapacity for work.

It is interesting to highlight the increasing incidence of lung cancer-related deaths in females during the study period, a tendency that has been observed at a global scale [23] and continues to pose a challenge for researchers. Nonetheless, a global decreasing tendency of cancer-related deaths has been described, yet important variations are observed per cancer typology [24]. Such trends must be taken into consideration for an adjusted distribution of resources. Equally, the increased years of potential productive life that are lost by the premature death of workers with ages between 50 and 59 years are noteworthy in order to develop adjusted programs.

\section{Conclusions}

The assessment of total productivity losses due to lung cancer provides new information that may assist decision makers in the allocation of resources. Lung cancer supposes a significant burden in Spain, with an increasing tendency in women that is reflected in the increasing number of YPPLL. The promotion of programs aiming to reduce the incidence of lung cancer in working-age individuals will presumably yield substantial reductions in productivity loss counts.

\section{Abbreviations}

DALYs: Disability-adjusted life-years; INE: Spanish national statistics institute (Instituto Nacional de Estadística); YPPLL: Years of potential productive life lost

\section{Acknowledgements}

Not applicable.

\section{Authors' contributions}

$J \mathrm{D}$ contributed to the investigation by interpreting the economic situation of lung cancer in Spain and was a major contribution in the intellectual content revision. AM analysed lung cancer situation in Spain, analysed and interpreted the statistical data, and was a major contributor in writing the manuscript. Both authors have read and approved the final manuscript.

\section{Funding}

Not applicable.

\section{Availability of data and materials}

The data that support the findings of this study are available from the Spanish national statistics institute at http://www.ine.es.

Ethics approval and consent to participate

Ethics committee approval and patient consent were not required for this study.

\section{Consent for publication}

Not applicable.

\section{Competing interests}

The authors declare that they have no competing interests.

\section{Author details}

'Department of Economics, Universitat de Barcelona, Diagonal 696, 08034 Barcelona, Spain. ${ }^{2}$ BCN Health Economics \& Outcomes Research S.L., Travessera de Gràcia, 62, 08006 Barcelona, Spain.

Received: 10 April 2019 Accepted: 3 October 2019

Published online: 23 October 2019

\section{References}

1. Sociedad Española de Oncología Médica. Las cifras del cáncer en España. https://seom.org/dmcancer/wp-content/uploads/2019/Informe-SEOM-cifrascancer-2019.pdf. Accessed 1 Apr 2019.

2. Global Burden of Disease Cancer Collaboration, Fitzmaurice C, Dicker D, Pain A, Hamavid H, Moradi-Lakeh M, et al. The Global Burden of Cancer 2013. JAMA Oncol. 2015;1(4):505-27.

3. Francisci S, Minicozzi P, Pierannunzio D, Ardanaz E, Eberle A, Grimsrud TK, et al. Survival patterns in lung and pleural cancer in Europe 1999-2007: results from the EUROCARE-5 study. Eur J Cancer. 2015;51(15):2242-53.

4. Cancer Research UK. Lung cancer mortality statistics. https://www. cancerresearchuk.org/. Accessed 1 Apr 2019.

5. Kozielski J, Kaczmarczyk G, Porębska I, Szmygin-Milanowska K, Gołecki M. Lung cancer in patients under the age of 40 years. Contemp Oncol (Pozn). 2012;16(5):413-5.

6. Oortwijn W, Nelissen E, Adamini S, van den Heuvel S, Geuskens G, Burdof L. Social determinants state of the art reviews - Health of people of working 
age - Full Report. Luxembourg: European Commission Directorate general for health and consumers; 2011. ISBN 978-92-79-18526-7

7. Zhang W, Bansback N, Anis AH. Measuring and valuing productivity loss due to poor health: a critical review. Soc Sci Med. 2011;72(2):185-92.

8. Kigozi J, Jowett S, Lewis M, Barton P, Coast J. Estimating productivity costs using the friction cost approach in practice: a systematic review. Eur J Health Econ. 2016;17(1):31-44.

9. Yabroff KR, Bradley CJ, Mariotto AB, Brown ML, Feuer EJ. Estimates and projections of value of life lost from cancer deaths in the United States. JNCI J Natl Cancer Inst. 2008;100(24):1755-62.

10. Bradley CJ, Yabroff KR, Dahman B, Feuer EJ, Mariotto A, Brown ML. Productivity costs of cancer mortality in the United States: 2000-2020. J Natl Cancer Inst. 2008;100(24):1763-70.

11. Carter HE, Schofield DJ, Shrestha R. The productivity costs of premature mortality due to cancer in Australia: evidence from a microsimulation model. PLoS One. 2016;11(12):e0167521.

12. Oliva-Moreno J. Loss of labour productivity caused by disease and health problems: what is the magnitude of its effect on Spain's economy? Eur J Health Econ. 2012;13(5):605-14.

13. Peña-Longobardo LM, Aranda-Reneo I, Oliva-Moreno J, Vall-Castello J. Pérdidas laborales ocasionadas por muertes prematuras en España: un análisis para el periodo 2005-2009. Rev Esp Salud Pública. 2015;89:39-50.

14. Instituto Nacional de Estadística (INE). Estadística de defunciones según la causa de muerte. http://www.ine.es/dyngs/INEbase/es/operacion.htm?c= Estadistica_C\&cid=1254736176780\&menu=resultados\&idp=1254735573175 Accessed 1 Apr 2019

15. Instituto Nacional de Estadística (INE). Encuesta de estructura salarial. http:// www.ine.es/dyngs/INEbase/es/operacion.htm?c=Estadistica_C\&cid=1254 736176918\&menu=resultados\&idp=1254735976595. Accessed 1 Apr 2019.

16. Instituto Nacional de Estadística (INE). Encuesta de población activa. http:// www.ine.es/dyngs/NEbase/es/categoria.htm?c=Estadistica_P\&cid=1254735 976594. Accessed 1 Apr 2019.

17. Pearce A, Bradley C, Hanly P, O'Neil C, Thomas AA, Molcho M, et al. Projecting productivity losses for cancer-related mortality 2011-2030. BMC Cancer. 2016;16(1):804.

18. Hanly P, Soerjomataram I, Sharp L. Measuring the societal burden of cancer: the cost of lost productivity due to premature cancer-related mortality in Europe. Int J Cancer. 2015;136(4):E136-45.

19. Luengo-Fernandez R, Leal J, Gray A, Sullivan R. Economic burden of cancer across the European Union: a population-based cost analysis. Lancet Oncol. 2013;14(12):1165-74.

20. Garrido P, Viñolas N, Isla D, Provencio M, Majem M, Artal A, et al. Lung cancer in Spanish women: the WORLD07 project. Eur J Cancer Care (Engl). 2019;28(1):e12941.

21. Oliva-Moreno J, Peña-Longobardo LM. Labour productivity loss caused by premature deaths associated with breast cancer: results from Spain over a 10-year period. Breast Cancer Res Treat. 2018;172(3):571-6.

22. Hanly P, Pearce A, Sharp L. The cost of premature cancer-related mortality: a review and assessment of the evidence. Expert Rev Pharmacoecon Outcomes Res. 2014;14(3):355-77.

23. Egleston BL, Meireles SI, Flieder DB, Clapper ML. Population-based trends in lung Cancer incidence in women. Semin Oncol. 2009;36(6):506-15.

24. Cabanes A, Vidal E, Aragonés N, Pérez-Gómez B, Pollán M, Lope V, et al. Cancer mortality trends in Spain: 1980-2007. Ann Oncol. 2010;21 (Suppl 3): iii14-20.

\section{Publisher's Note}

Springer Nature remains neutral with regard to jurisdictional claims in published maps and institutional affiliations.

Ready to submit your research? Choose BMC and benefit from:

- fast, convenient online submission

- thorough peer review by experienced researchers in your field

- rapid publication on acceptance

- support for research data, including large and complex data types

- gold Open Access which fosters wider collaboration and increased citations

- maximum visibility for your research: over $100 \mathrm{M}$ website views per year

At $\mathrm{BMC}$, research is always in progress.

Learn more biomedcentral.com/submissions 